\title{
Técnicas de visualização: educação online em tempos difíceis
}

\author{
Visualization techniques: online education in hard times
}

\author{
Bárbara Emanuel
}

educação, técnicas de visualização, estratégias didáticas

Este trabalho relata experiências em uma disciplina prática sobre técnicas de visualização, lecionada em 2020, durante a pandemia de covid-19. Desenvolvida a partir de princípios de Educação Online, a disciplina baseou-se também em questões emocionais e lúdicas, além de questões de acessibilidade. No contexto de emergência sanitária, foi preciso planejar o conteúdo e as atividades práticas de forma a atender novas necessidades: exercícios sem uso de computador ou softwares de criação digital, estruturação do conteúdo para acesso assíncrono, construção colaborativa de conhecimento. Os resultados apontaram possibilidades e pontos de atenção não apenas para disciplinas lecionadas remotamente, como também para a prática em sala de aula.

education, visualization techniques, teaching strategies

This is a course case, presenting experiences from a practice-based course on visualization techniques, taught during the 2020 covid-19 pandemics. The development of the course followed principles of Online Education, also considering aspects of accessibility and emotional connection. The sanitary emergency presented us with new challenges, so the course had to be planned accordingly - computer-free and software-free exercises, content asynchronously accessed, collaborative knowledge building. Results point towards possibilities and challenges, not only in remotely taught courses, but also in-class teaching.

\section{Introdução}

Em março de 2020, entraram em vigor medidas de enfrentamento à pandemia de covid-19, impedindo a realização de aulas presenciais. Nosso primeiro semestre letivo de 2020 começou então apenas em setembro, com atividades remotas. Com alunos em casa, sem acesso aos equipamentos da universidade, como lecionar disciplinas práticas, que costumam ser oferecidas em laboratórios?

Este trabalho traz experiências vividas na disciplina Técnicas de Visualização, planejada inicialmente para uma sala com computadores, softwares de criação e acesso à internet, mas que precisou ser oferecida remotamente. Como fazer gráficos sem o Illustrator? Como desenvolver habilidades cartográficas sem mapas digitais? Como mostrar princípios de visualização a distância? Como propor atividades quando o mundo está acabando e as pessoas estão assustadas?

A disciplina é oferecida como optativa em uma universidade pública no estado do Rio de Janeiro. No período em questão, a turma era composta por alunos de quatro diferentes cursos

Anais do $10^{\circ} \mathrm{CIDI}$ e $10^{\circ} \mathrm{CONGIC}$

Kelli C.A.S. Smythe, Rafael de Castro Andrade (orgs.)

Sociedade Brasileira de Design da Informação - SBDI

Curitiba | Brasil | 2021
Proceedings of the $10^{\text {th }} \mathrm{CIDI}$ and $10^{\text {th }}$ CONGIC

Kelli C.A.S. Smythe, Rafael de Castro Andrade (orgs.)

Sociedade Brasileira de Design da Informação - SBDI Curitiba | Brazil | 2021 
de graduação: Jornalismo, Publicidade, Desenho Industrial e Estudos de Mídia. A ementa cobre questões de representação visual, como elementos primários e uso do campo bidimensional, princípios de composição, uso de cores, e desenvolvimento de visualizações de diferentes tipos.

A adaptação da disciplina começou com a escolha do modelo de ensino-aprendizagem. Discussões no âmbito da instituição giravam em torno de diferentes possibilidades, como o ensino remoto emergencial e o ensino a distância tradicional. Os princípios do ensino remoto emergencial variam de acordo com a instituição, tendo, em algumas, transmissão síncrona de aulas cobrindo a carga horária completa de cada disciplina. Ou seja, as aulas permanecem como antes, só que transmitidas ao vivo pela internet. Este modelo tem a vantagem da rápida adaptação, necessária principalmente para as instituições que retomaram imediatamente as atividades de forma remota. No entanto, esta carga completamente síncrona é um desafio para alunos e professores com acesso deficiente à internet, já que exige transmissão de uma quantidade grande de dados.

Já o ensino a distância tradicional é baseado na autoaprendizagem, na qual alunos aprendem sozinhos a partir de conteúdos e atividades, em uma abordagem instrucionista unidirecional, mediada pelo material didático (Santos, 2009; Pimentel e Carvalho, 2020). Há automação e padronização, que facilitam a distribuição para centenas de alunos ao mesmo tempo, mas que, por outro lado, subtraem oportunidades de trocas e de colaboração com o professor e entre os alunos.

O modelo usado como base para esta disciplina não foi nem o remoto emergencial nem o a distância tradicional, mas a Educação Online (Santos, 2009; Pimentel e Carvalho, 2020). Santos (2009, p.5663) define a educação online como "o conjunto de ações de ensino-aprendizagem ou atos de currículo mediados por interfaces digitais que potencializam práticas comunicacionais interativas e hipertextuais". Neste modelo, a autoaprendizagem acontece junto à aprendizagem colaborativa. Há material didático e momentos individuais de leitura, reflexão e produção, mas também interatividade entre os participantes, de forma síncrona e assíncrona.

Pimentel e Carvalho (2020, n.p.) enumeram oito princípios da Educação Online:

1) Conhecimento como "obra aberta": "em construção sem fim, que convida à ressignificação, interferência, completação, autoria e cocriação";

2) Curadoria de conteúdos online;

3) Ambiências computacionais diversas, indo além do ambiente virtual de aprendizagem;

4) Aprendizagem colaborativa;

5) Conversação entre todos, incluindo em grupo e em particular, de forma síncrona e assíncrona, e em tons formal e informal;

6) Atividades autorais;

7) Mediação docente ativa; e

8) Avaliação baseada em competências, formativa e colaborativa. 
O uso emergencial de tecnologias de informação e comunicação não é equalitário, considerando as diferenças socioeconômicas entre os alunos. Enquanto alguns dispõem de computador de uso pessoal, espaço doméstico adequado e conexão de internet em alta velocidade, outros contam apenas com smartphones e pacotes de dados móveis, dividindo espaços e tarefas familiares. Com o privilégio de atividades, conteúdo e interação assíncronos, o acesso mostra-se mais democrático que no modelo de ensino remoto emergencial, com suas aulas inteiramente síncronas. Assincronamente, alunos podem acessar o ambiente virtual de aprendizagem nos momentos mais convenientes e pelo tempo adequado para sua realidade. Além disso, a disciplina contou com um canal no YouTube, com vídeos produzidos especialmente, e um blog, com resumos textuais dos vídeos.

Além do modelo pedagógico, era preciso considerar aspectos emocionais, em meio a uma emergência sanitária. A pandemia trouxe não apenas o distanciamento social e suas consequências psicológicas, como também o surgimento ou agravamento de insegurança econômica, devido à perda de renda durante a pandemia, e de conflitos domésticos, já que muitos alunos retornaram a um intenso convívio familiar. Nesse sentido, a combinação de autoaprendizagem e colaboração da Educação Online permite momentos de interação entre os alunos, importantes para a construção e manutenção de redes de apoio e afeto durante o período de isolamento social. Questões emocionais também serviram como norte para a inclusão de aspectos lúdicos tanto nos materiais didáticos produzidos para a disciplina, quanto nas atividades propostas.

Para o conteúdo programático da disciplina, foram selecionados temas relevantes para a criação de visualizações, organizados em dois grupos:

a) princípios fundamentais de comunicação, incluindo elementos visuais básicos, princípios de composição e teoria da cor, apoiados principalmente em Dondis (2003), Lupton e Philips (2015), Frutiger (2001), Fraser e Banks (2007), Holtzschue (2011) e Itten (2001); e

b) visualizações, incluindo instruções, processos, narrativas, dados e mapas, com base teórica, entre outros, de Cairo $(2016,2019)$, Roam (2008), Emanuel (2010), Tyner (2010) e Monmonier (1996).

A principal estratégia didática para possibilitar a prática frente às limitações e especificidades deste período de exceção foi voltar-se para o digital nas interações e para o analógico na execução das atividades. Enquanto a disponibilização de materiais didáticos e a interação entre a turma aconteceram principalmente no ambiente virtual de aprendizagem, a execução das atividades foi feita distante de telas digitais, utilizando o telefone celular apenas para fotografar. Além de servir como descanso do uso intenso de dispositivos digitais e como forma de promover a equidade entre alunos com diferentes tipos de acesso a computadores, esta abordagem estimulou uma maior abrangência nas tomadas de decisão projetuais, em comparação ao uso de softwares e aplicativos, que oferecem modelos e predefinições. 


\section{Metodologia / princípios norteadores}

A adaptação para o ambiente online considerou questões presentes na sociedade em geral e na universidade. No começo da pandemia, a instituição realizou uma pesquisa quantitativa para apurar as condições dos alunos em relação a acesso a tecnologias, a condições econômicas e laborais, e à situação doméstica. Os resultados, no entanto, não foram estatisticamente relevantes, dado que a pesquisa teve poucas respostas em relação ao universo do corpo discente. O centro acadêmico e coordenações de cursos promoveram, então, assembleias com grupos de alunos, a fim de traçar um diagnóstico qualitativo. A partir dos relatos e de observações próprias, e baseando-me nos princípios da Educação Online, defini princípios norteadores para o desenvolvimento da disciplina.

Considerando que muitos alunos não têm acesso a internet de qualidade em casa:

- Nenhum conteúdo deveria ser exclusivo de encontros síncronos, devendo ser também disponibilizado de forma assíncrona.

- Deveriam ser feitos resumos textuais dos vídeos, com imagens leves, publicados no blog da disciplina.

Considerando que muitos alunos não têm computadores para uso pessoal, mas possuem smartphones:

- Todo conteúdo deveria ser acessível por smartphones.

- Nenhuma atividade poderia exigir o uso de computador.

Considerando que muitos alunos estão trabalhando e/ou responsáveis por tarefas domésticas e cuidados com familiares:

- Deveria haver flexibilidade no que se refere ao acesso ao conteúdo e à entrega de atividades.

- Privilégio de conteúdo e interação assíncronos, para que cada aluno pudesse participar de acordo com suas possibilidades.

- O conteúdo de cada módulo deveria ficar disponível no ambiente virtual de aprendizagem de forma organizada a partir do seu lançamento até o final da disciplina, para que pudesse ser acessado a qualquer momento.

Considerando que muitos alunos não têm espaço adequado para a concentração:

- Todo conteúdo deveria ser dividido em pequenas doses.

- Privilégio de interação assíncrona.

Considerando que muitos alunos estão enfrentando estresse, ansiedade e depressão: 
- A disciplina deveria ter um fórum de apresentação, no qual os alunos pudessem se conhecer, apesar da distância física.

- Deveria haver estímulo à interação entre os alunos.

- O material didático deveria incluir alívios cômicos, como gifs animados e referências à cultura pop.

- As atividades deveriam ter aspectos lúdicos, autorais e de expressão pessoal.

- A mediação docente no mural da disciplina deveria ser acolhedora, privilegiando uma linguagem leve e construtiva.

Considerando a inclusão e a acessibilidade:

- Deveria haver um resumo textual de cada vídeo, com imagens (arquivos leves) com descrição, contemplando alunos com deficiências intelectuais cognitivas, alunos que usem tecnologias de narração, e os com acesso de baixa qualidade à internet.

Considerando os pontos salientados até aqui, a avaliação deveria ser formativa, ou seja, feita de forma contínua ao longo de cada disciplina, e considerando não apenas o desempenho nas atividades propostas, como também a participação com comentários. O fechamento de notas deveria ser feito junto com cada aluno, para que pudesse ser feita também uma autoavaliação e uma avaliação por pares.

\section{Resultados}

A carga horária de duas horas semanais (30 horas no total do período) da disciplina foi dividida em $25 \%$ para encontro síncrono e $75 \%$ para acesso ao conteúdo, realização de atividades e interação assíncrona. Atividades complexas duraram mais de uma semana, permitindo mais tempo tanto para a execução, quanto para os comentários. Os encontros trataram do tema da semana anterior, seguindo um conceito de sala de aula invertida, no qual alunos acessam conteúdos antes das aulas. Ao final do encontro, eram lançados o conteúdo e a atividade do módulo seguinte. Durante a semana, a interação acontecia no ambiente virtual de aprendizagem, incluindo o mural (onde os alunos podiam postar e comentar livremente) e um fórum de dúvidas específico para cada módulo, no qual alunos podem participar com comentários públicos ou com mensagens privadas para a professora.

O conteúdo foi estruturado em três categorias: essencial, complementar e colaborativo. $\mathrm{O}$ conteúdo essencial - disponibilizado no ambiente virtual de aprendizagem, no YouTube e no blog da disciplina - trazia questões fundamentais para cada módulo. Foram produzidos vídeos curtos, cobrindo aspectos teóricos e práticos, incluindo referências cotidianas e à cultura pop, a fim de tornar o conteúdo mais interessante e bem-humorado para os alunos. Outro desafio do ensino remoto, especialmente no conteúdo assíncrono, é a perda das expressões corporais e faciais do professor, que são amenizadas frente às câmeras. Para contornar esta questão, foram incluídos gifs animados nos vídeos, com expressões faciais exageradas (geralmente 
usando memes ou celebridades, conhecidos pelos alunos) adequadas para cada situação ou seja, as expressões que o professor teria se estivesse falando sobre aquele assunto em aula. Os alunos postaram comentários no ambiente virtual de aprendizagem e em redes sociais elogiando a iniciativa, comentando que ela facilitou o entendimento do conteúdo e ajudou a tornar a disciplina leve e prazerosa.

O conteúdo complementar foi fruto de um trabalho de curadoria, indicando, em cada módulo, materiais que permitissem o aprofundamento dos temas abordados. Estes itens incluíram artigos científicos, tutoriais, jogos online, sites, vídeos e trechos de livros.

A partir dos conteúdos e das atividades, houve conversações no ambiente virtual de aprendizagem, com contribuições de todos, a partir de práticas usuais na cultura contemporânea de redes sociais: postar, comentar, compartilhar e colaborar, colocando-se como curador, autor e coautor. A partir desta produção de sentido, formou-se o conteúdo colaborativo da disciplina.

A disciplina foi organizada em oito módulos, além da abertura e do fechamento. O módulo de abertura introduziu o conceito de composição visual e teve como atividade a participação no fórum de apresentação. Cada aluno respondeu contando seu curso, período, expectativas para a disciplina e sugestões. Entre as expectativas, foi citada, principalmente, a vontade de adquirir uma base teórica que permitisse a execução consciente de peças visuais, indo além do "achismo" (interessante notar que nenhum aluno declarou a expectativa de aprender a usar algum software de criação). Já as sugestões concentraram-se nas atitudes desejadas: paciência, empatia, compreensão, diálogo e colaboração. A atividade seguiu no módulo 01 , que abordou questões fundamentais de comunicação - repertório, contexto e representação.

O módulo 02 apresentou elementos básicos de composições visuais: ponto, linha, forma, cores e textura, a partir de autores como Dondis (2003), Frutiger (2001) e Lupton e Philips (2015). A atividade prática foi a criação de duas composições abstratas usando linhas que expressassem personalidades específicas (misteriosa, ousada, romântica, nervosa ou raivosa). O uso de materiais era livre, e os alunos aproveitaram a oportunidade para experimentar com esmaltes, maquiagem e purpurina, entre outros. Cada aluno postou suas criações no mural da disciplina sem dizer as personalidades que escolheram, para que os colegas pudessem comentar tentando acertar. Assim, foi possível não apenas testar a eficiência comunicativa das imagens, como também promover uma interação lúdica entre a turma. A participação foi grande, com a brincadeira de identificação da personalidade das linhas, e os alunos demonstraram habilidades tanto de expressão quanto de análise. 
Figura 1: Linhas e materiais usados — nervosa e ousada, criação de Aline Azevedo

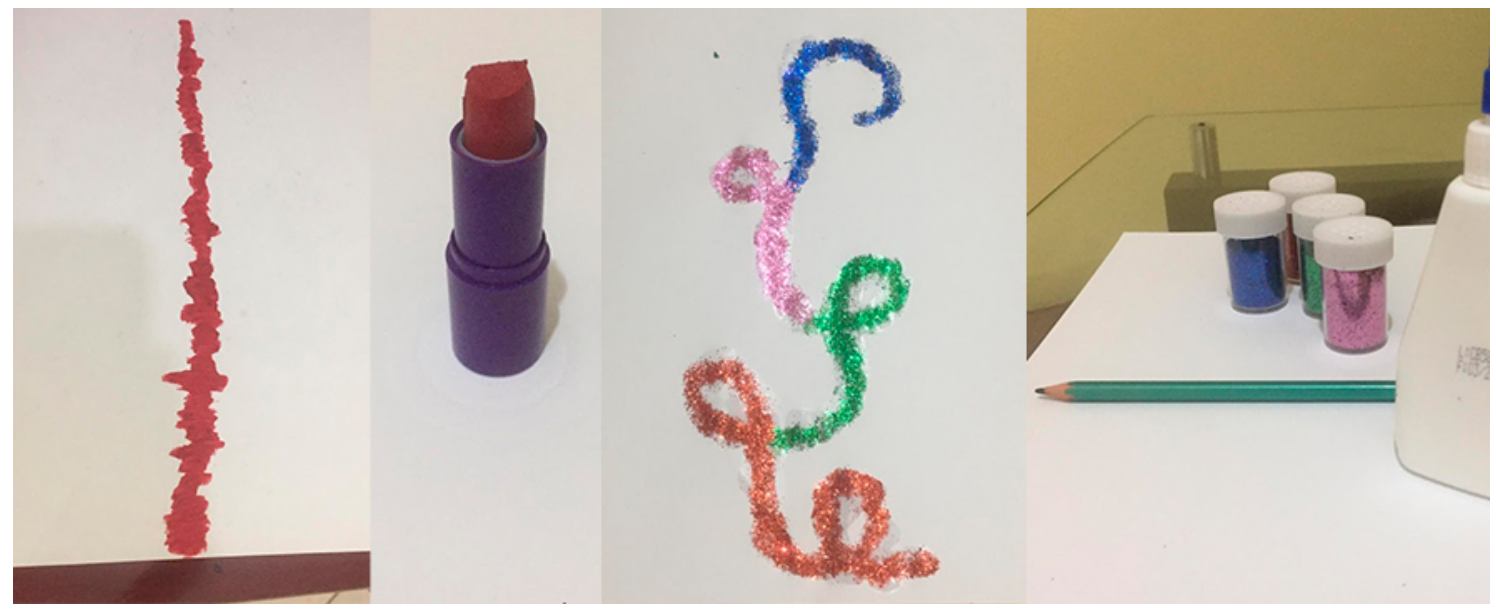

Figura 2: Linhas e materiais usados — misteriosa e romântica, criação de Thais Gesteira

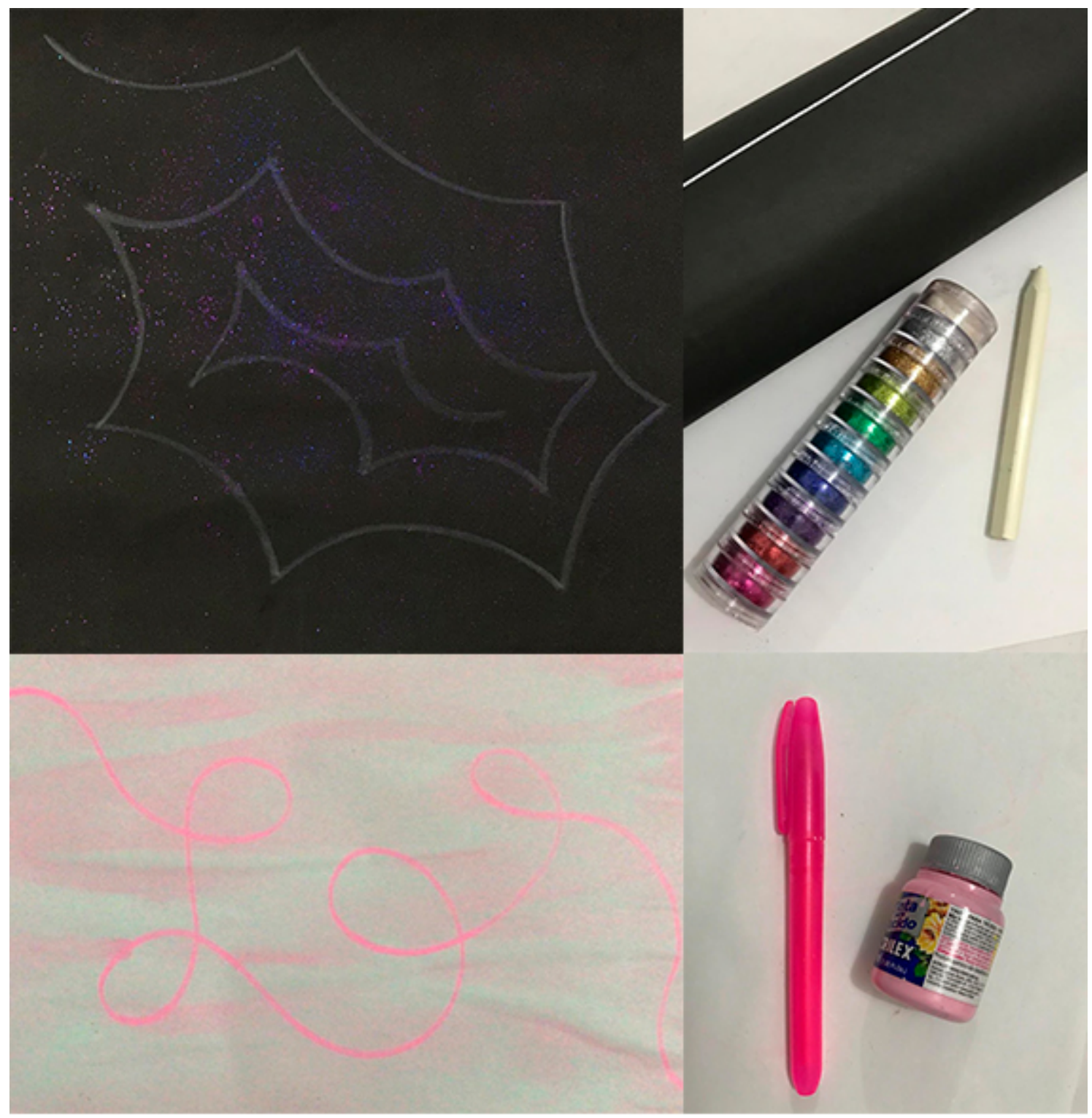


O módulo 03 tratou de princípios de composição: equilíbrio, escala, ênfase, ritmo e movimento. A atividade foi inspirada em exercício apresentado no livro Novos Fundamentos do Design (Lupton e Philips, 2015). Usando o smartphone, os alunos deveriam tirar fotografias explorando a percepção de diferentes relações de escala para um mesmo objeto. As composições deveriam estar equilibradas visualmente, além de aplicar outros princípios discutidos no módulo. Antes de fotografar, cada aluno deveria considerar questões como:

- Qual objeto, dos que eu tenho em casa, funciona bem para isso?

- Em que diferentes contextos ele pode ser inserido para dar diferentes ideias de tamanho?

- Considerando que escala é comparação, que outros objetos eu posso usar na composição?

- Que diferentes enquadramentos podem ser usados?

Além de desenvolver e demonstrar habilidades de composição, a atividade voltou o olhar para o ambiente doméstico - onde estávamos passando muito tempo, em isolamento social - com uma curiosidade específica, exploratória e criativa. Alguns alunos demonstraram dificuldade com os princípios de composição, especialmente equilíbrio e ênfase, mas a maioria obteve sucesso na manipulação da escala. Isto me fez considerar a possibilidade de, em uma próxima aplicação da disciplina, trocar a atividade por uma que exercite principalmente o equilíbrio visual.

Figura 3: Escala, criação de Fátima Moraes

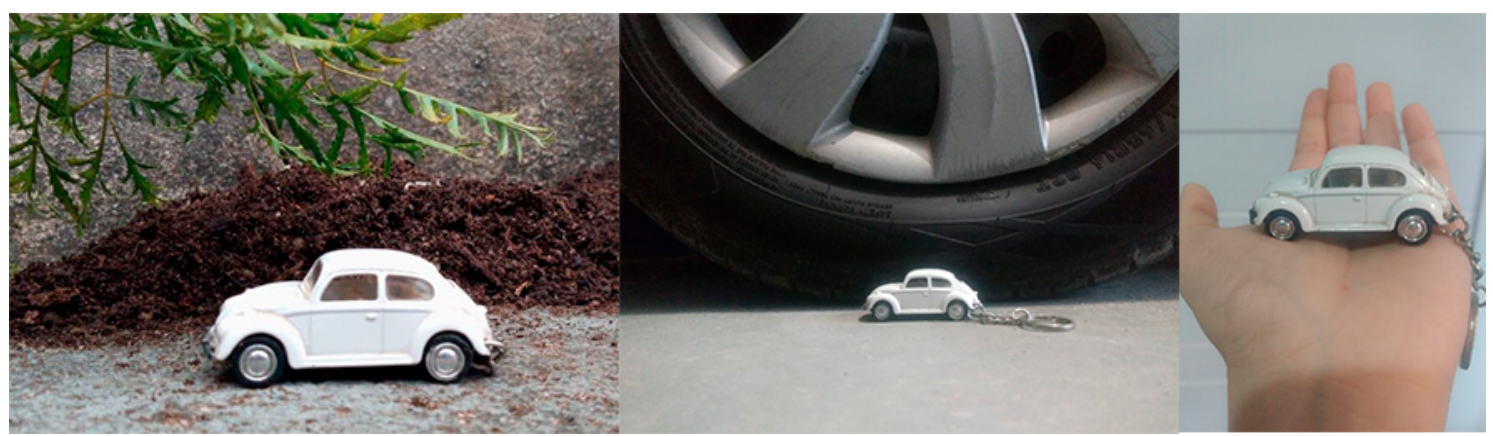

Figura 4: Escala, criação de Gabrielle Fonseca
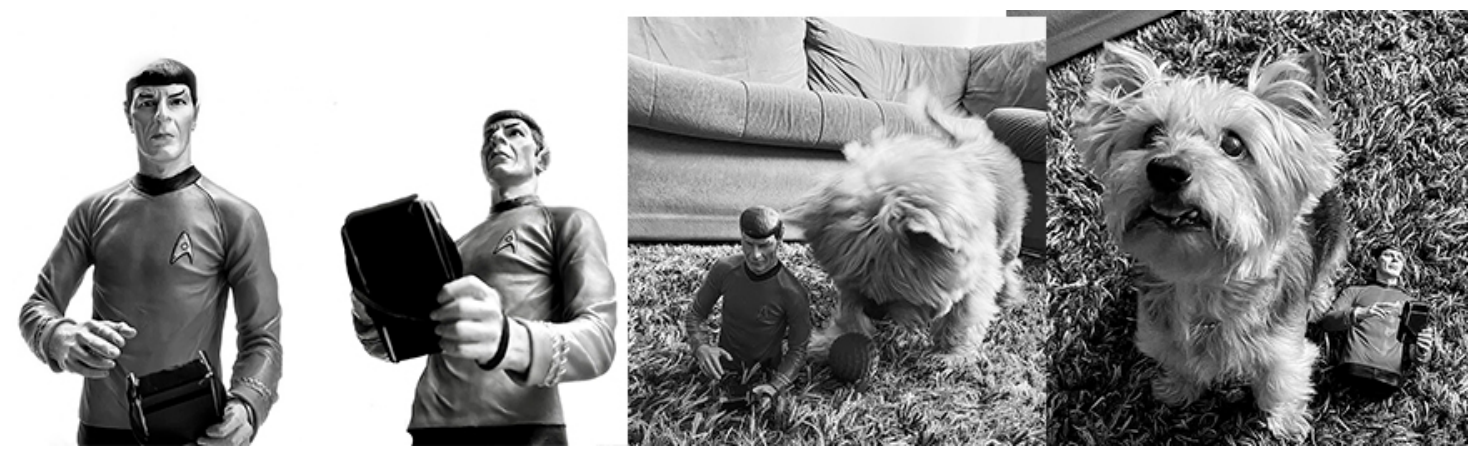
Figura 5: Escala, criação de Raphaela Moraes

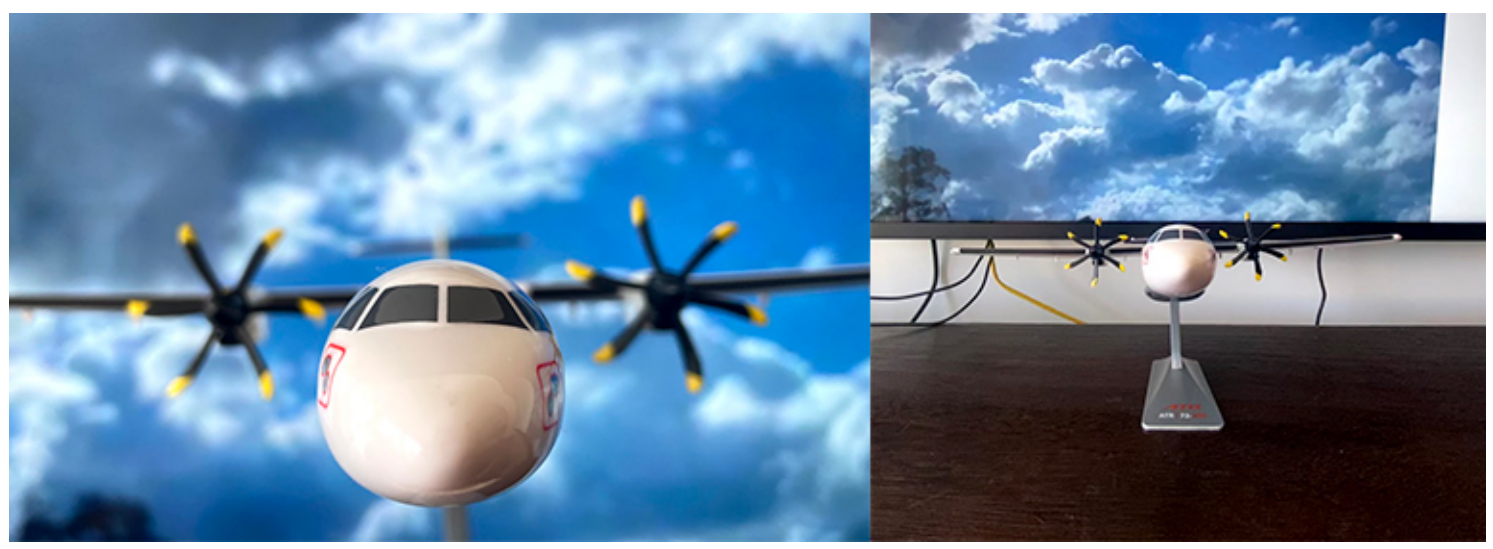

O módulo 04 tratou de cores, a partir de autores clássicos (Albers, 1975; Itten, 2001) e contemporâneos (Fraser e Banks, 2007; Holtzschue, 2011; McCloud, 2005). O conteúdo incluiu princípios básicos de teoria das cores - sistemas de cor, círculos cromáticos, aspectos da cor (matiz, saturação, valor) e harmonias cromáticas - além de aspectos comunicacionais. A atividade prática foi a produção de quatro fotografias, cada uma apresentando uma das seguintes harmonias cromáticas: monocromática, complementar, análoga e triádica. Os alunos deveriam fotografar objetos dentro de suas próprias casas, respeitando a situação de isolamento social diante da emergência sanitária. Deveriam também dar um título para cada composição, expressando algo relacionado à harmonia cromática da imagem. Assim, além de fixarem o conteúdo relacionado ao círculo cromático, eles consideraram aspectos comunicacionais das cores. A atividade também funcionou como um exercício do olhar, propondo que os alunos se voltassem para o ambiente doméstico - ao qual estavam forçosamente confinados - com novos olhos, buscando cores e significados, redescobrindo objetos cotidianos. A principal dificuldade apresentada nos resultados foi a diferenciação entre as harmonias monocromática e análoga, que requer um olhar sensível para pequenas variações de matiz. De maneira geral, no entanto, a atividade foi bem-sucedida, com demonstração não apenas de conhecimentos sobre cores, como também sobre composição visual. Os alunos relataram terem se divertido descobrindo combinações de cores em casa. 
Figura 6: Harmonias cromáticas - monocromática "relax", análoga "lembrança", complementar "cuidado \& carinho", triádica "união faz a força”. Criação de Raíssa Testahy

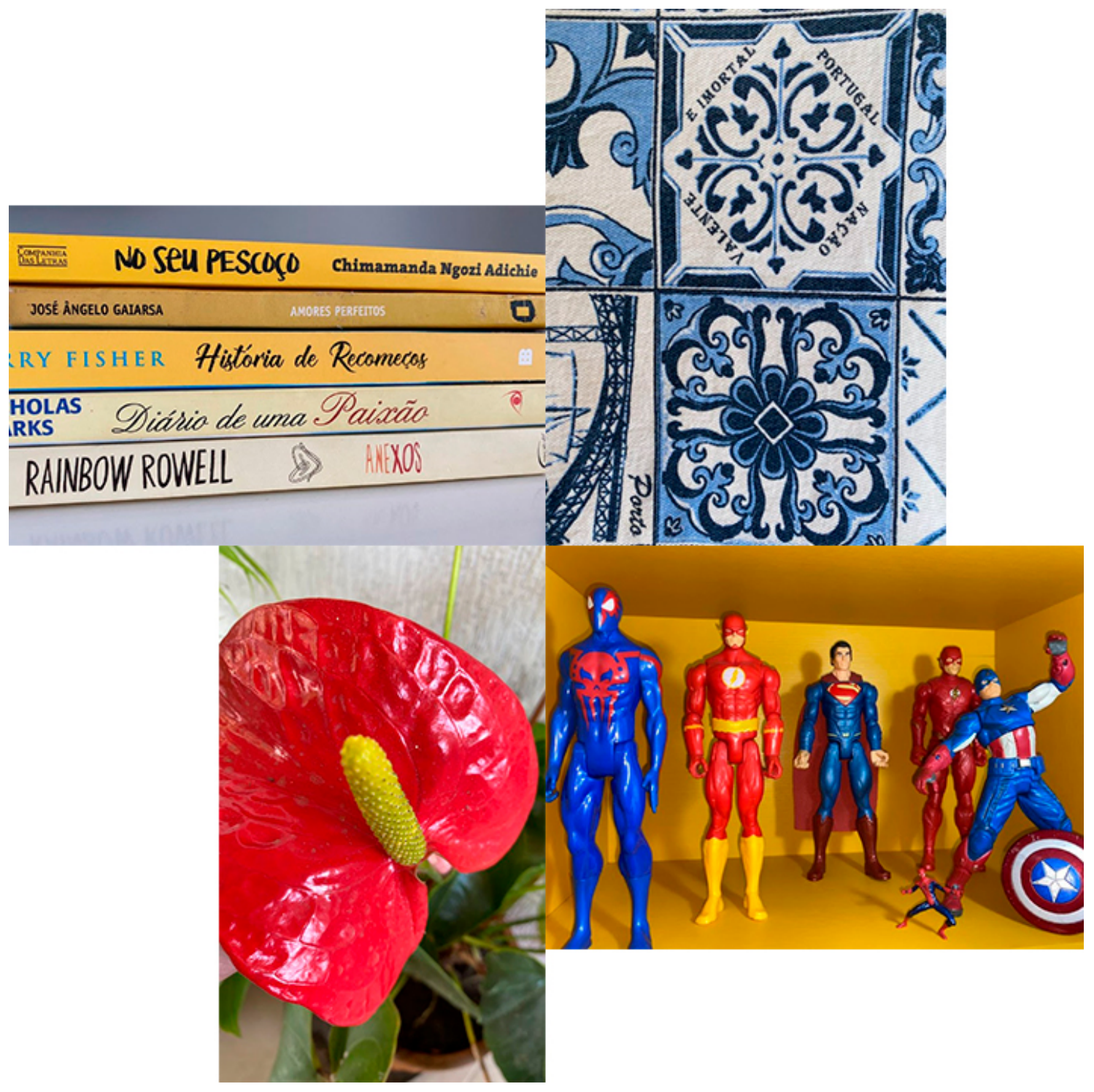


Figura 7: Harmonias cromáticas - monocromática "apenas busquem conhecimento", análoga "category is calor", complementar "imaginação", triádica "faxina". Criação de Marcos Castilho

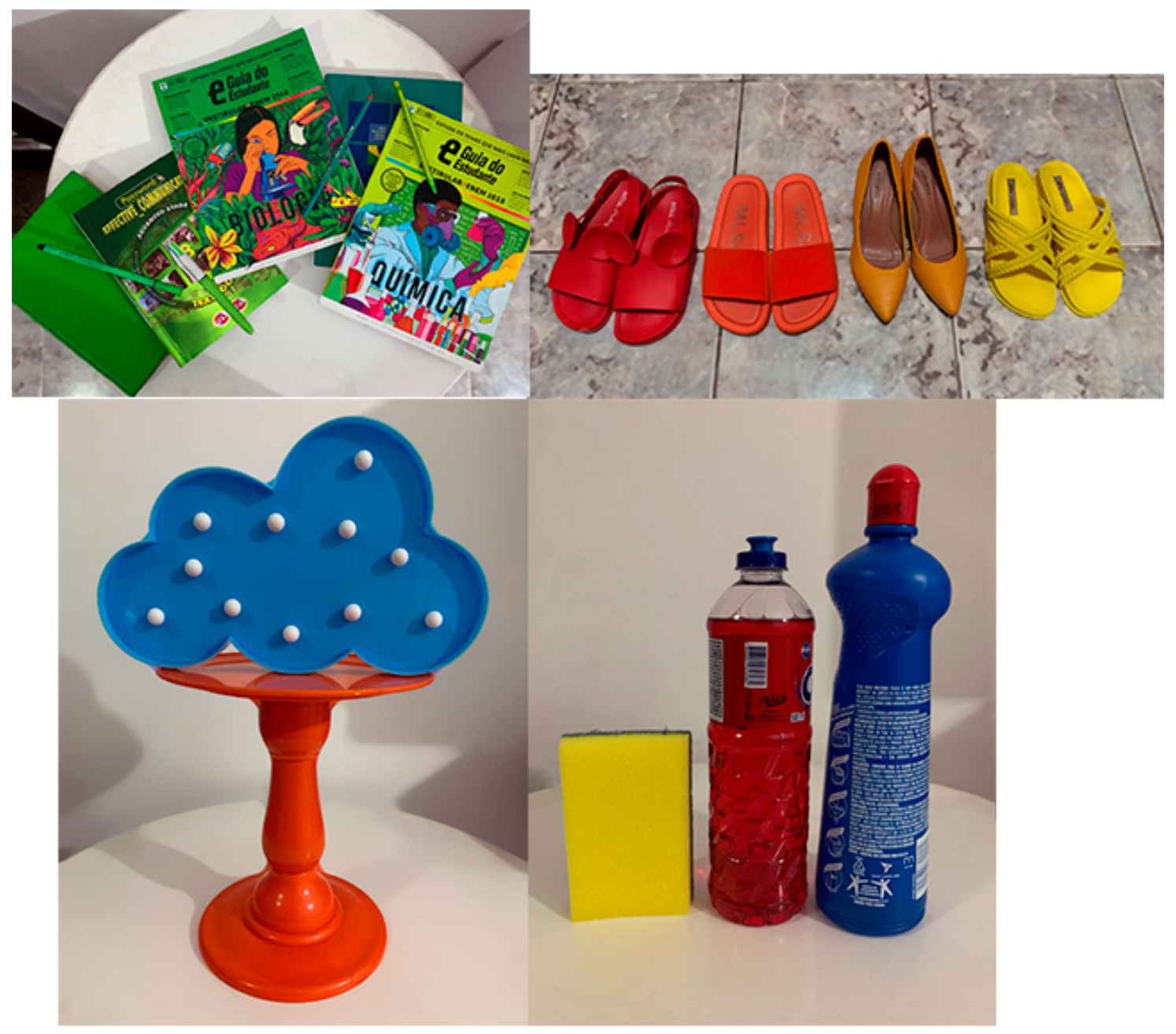


Figura 8: Harmonia cromáticas - monocromática "verde verdadeiro", análoga "carregando", complementar "rastelo catimbum", triádica "celeiro do mundo". Criação de Heitor Delpupo

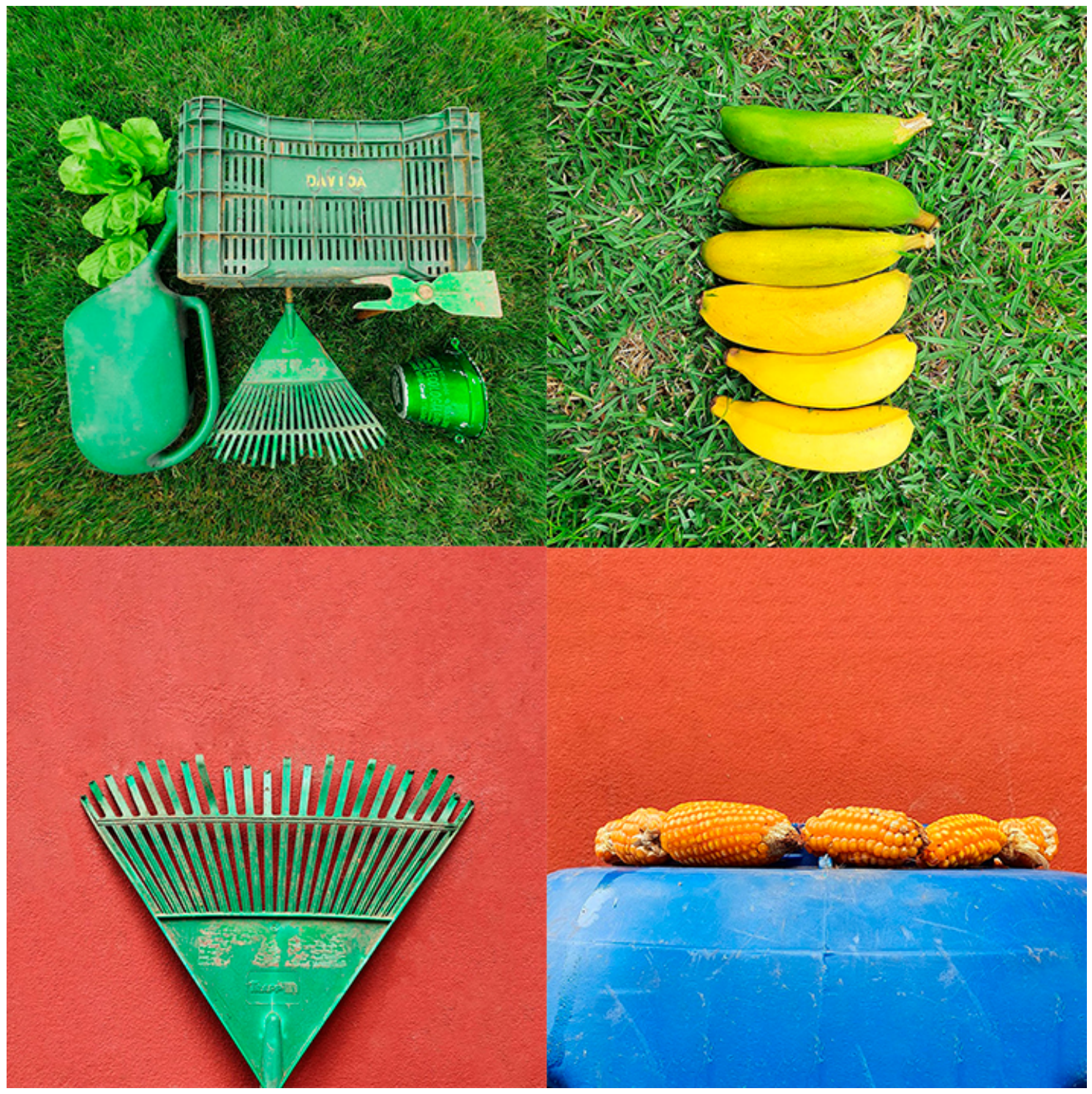

O quinto módulo abriu o segundo bloco da disciplina, introduzindo definições fundamentais de visualizações. Além disso, foi apresentado o método "olhar, ver, imaginar, mostrar", descrito no livro The Back of the Napkin (Roam, 2008). Não houve proposta de atividade, já que o objetivo do módulo era a apreensão de conteúdo essencial para a execução de atividades de média complexidade nos três módulos seguintes.

O módulo seis apresentou questões específicas da visualização de instruções, processos e narrativas. A atividade proposta foi a visualização de uma narrativa - filme, livro, série ou desenho animado - que mostrasse alguma sequência de eventos. A visualização deveria ser feita à mão, ou seja, sem ferramentas digitais. A atividade cobriu pontos trabalhados nos módulos anteriores, pedindo que os alunos considerassem as seguintes questões:

- Que elementos fazem parte do repertório de quem assistiu a narrativa? E de quem não assistiu? 
- Como os elementos básicos (pontos, linhas, formas, texturas) estão expressando algo?

- O que enfatizar? Como? Que elementos visuais são apenas de apoio?

- Que cores usar? Por quê?

Os alunos escolheram narrativas com diferentes níveis de complexidade. Alguns alunos demonstraram dificuldade com a diferenciação entre eventos consecutivos e concomitantes, enquanto outros visualizaram relações entre personagens, em vez de sequências de eventos. A maioria, no entanto, foi bem-sucedida, aplicando pontos vistos neste módulo e nos anteriores.

Figura 9: Narrativas — "As muitas mortes dos irmãos Winchester", criação de Daiani Oliveira

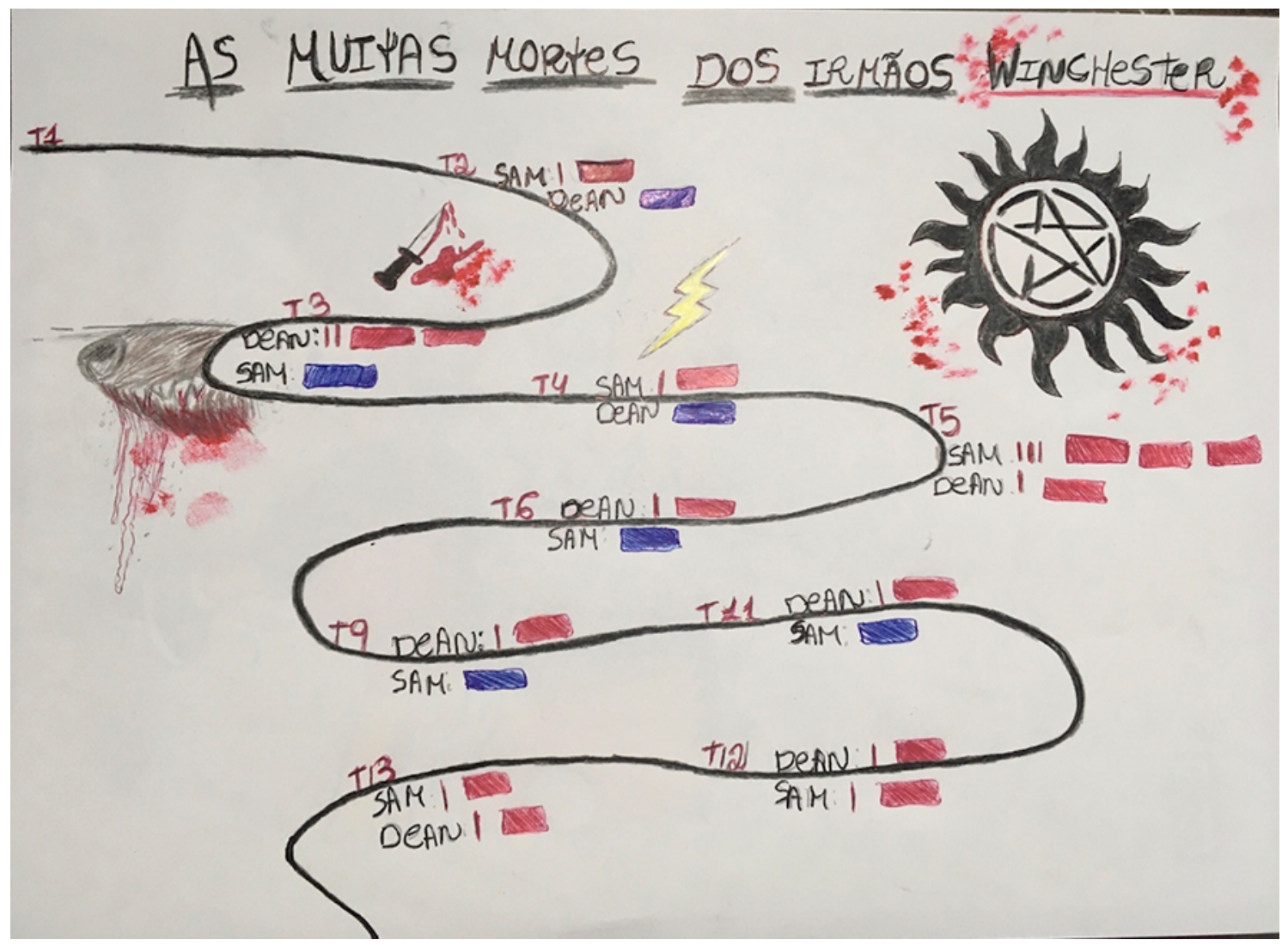


Figura 10: Narrativas — "A força de Lorde Voldemort ao longo da saga Harry Potter", criação de Nathalia Teixeira

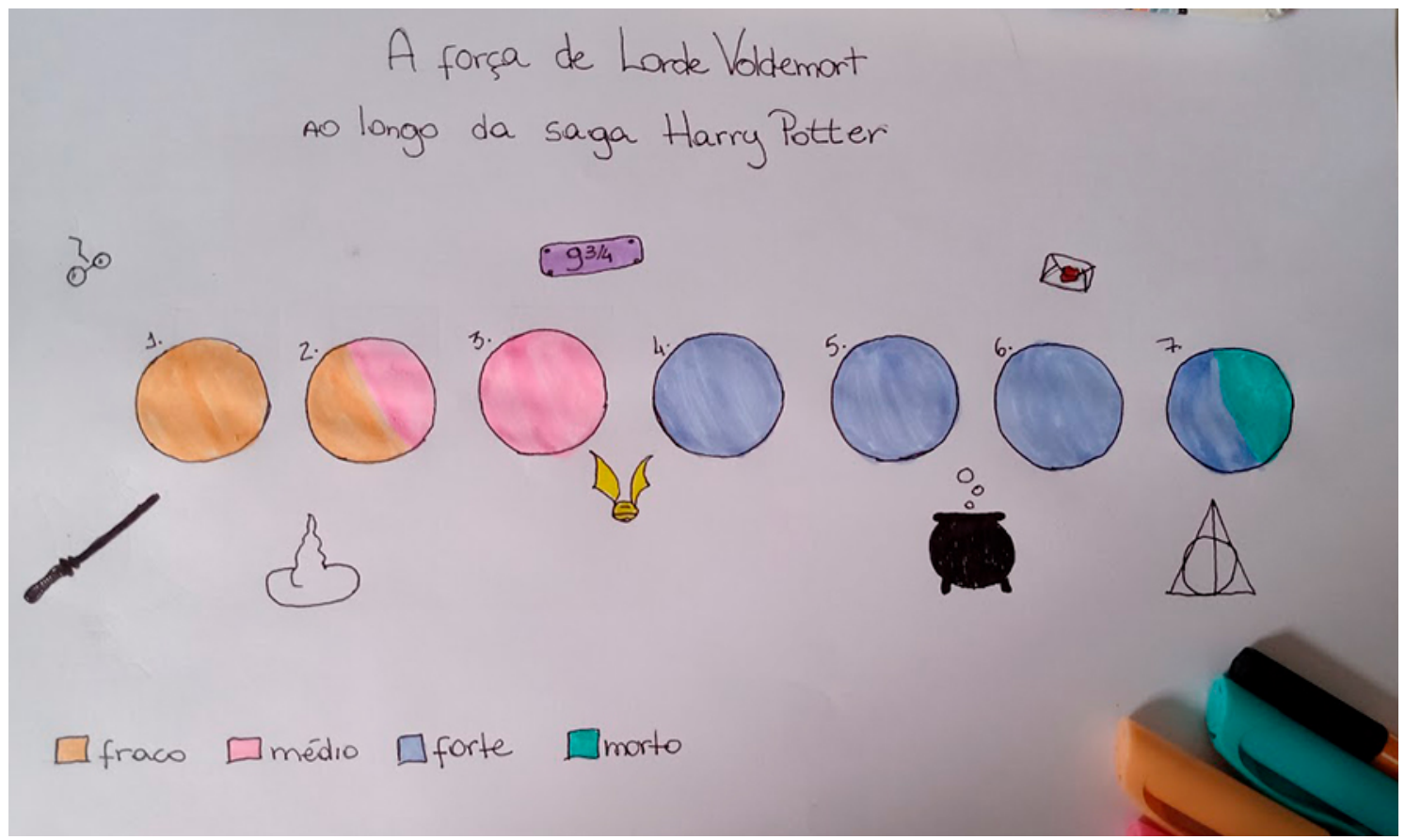

Figura 11: Narrativas - "fusões de steven universe (primeiras aparições)", criação de Thais Marques

\section{fusões de steven universe (primeiras apariydes)}

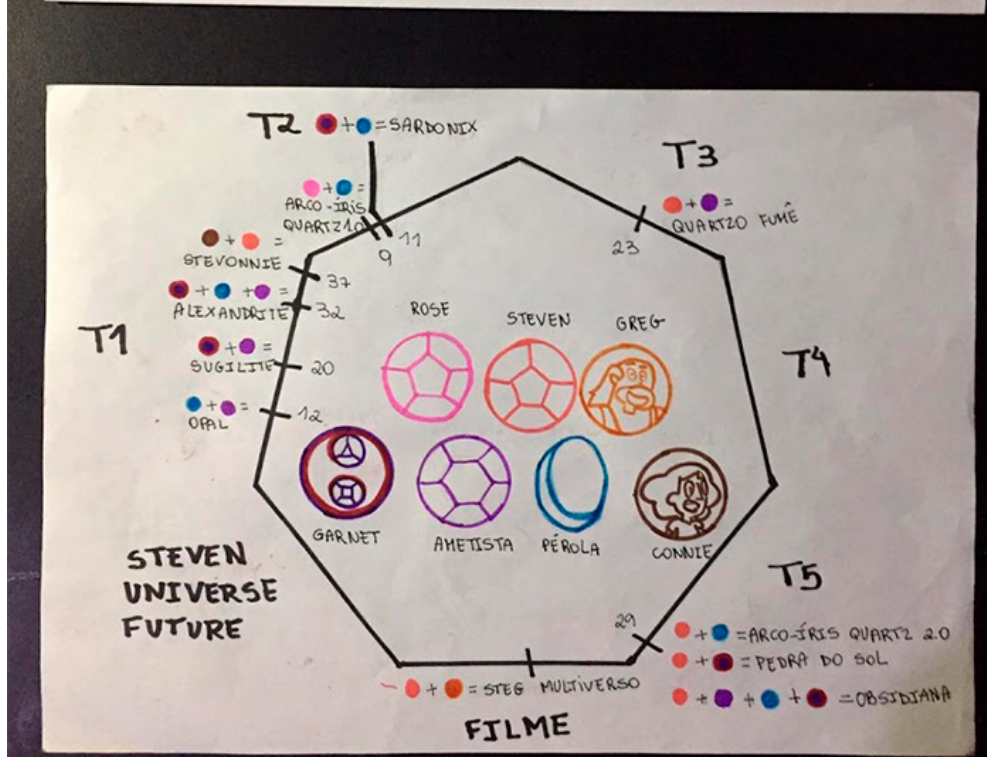


O sétimo módulo concentrou-se em mapas, especialmente nos princípios de cartografia (Krygier e Wood, 2011; Tyner, 2010) e em aspectos retóricos (Monmonier, 1996; Emanuel, 2010). A atividade propôs a criação de um mapa persuasivo, ou seja, feito de forma a atrair visitantes. O lugar representado deveria ser o destino dos sonhos do aluno - um lugar onde ele nunca esteve, mas gostaria muito de ir um dia. Esta delimitação pedia uma pesquisa sobre o local, em vez de produção a partir de memórias, e trazia um componente lúdico e emocional, estimulando a imaginação e o envolvimento afetivo, com sonhos e planos para um futuro póspandêmico. O mapa deveria ser feito à mão e, como apoio, foram apresentados os livros How to make hand-drawn maps (Cann, 2018) e The Art of Map Illustration (Hancock et al, 2018). A participação dos alunos foi grande, tanto com a execução quanto com comentários. Eles arriscaram-se na produção de ilustrações, apesar de nunca terem tido, na sua maioria, aulas nesse sentido. A seleção de pontos de interesse de modo a informar e persuadir foi coerente e, em alguns deles, seguiu temas específicos, como "futebol", "lua de mel", "decolonial", "Senhor dos Anéis" e "igrejas". Alguns alunos relataram que a atividade foi um momento de relaxamento e diversão, "quase uma terapia".

Figura 12: Mapas — “Japão”, criação de Ana Luiza Soares

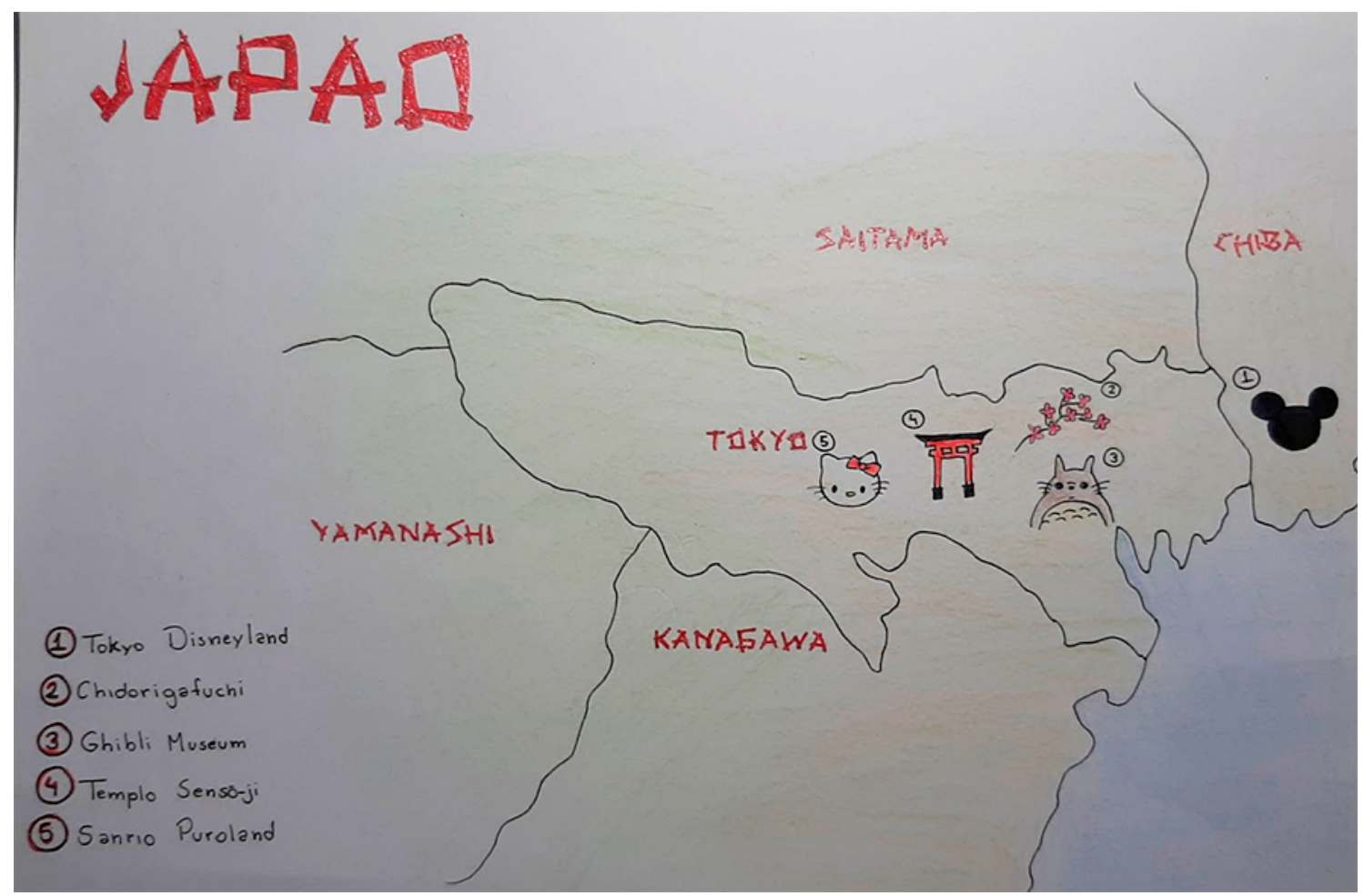


Figura 13: Mapas - "Parque Nacional da Chapada dos Veadeiros”, criação de Raphaela Fernandes

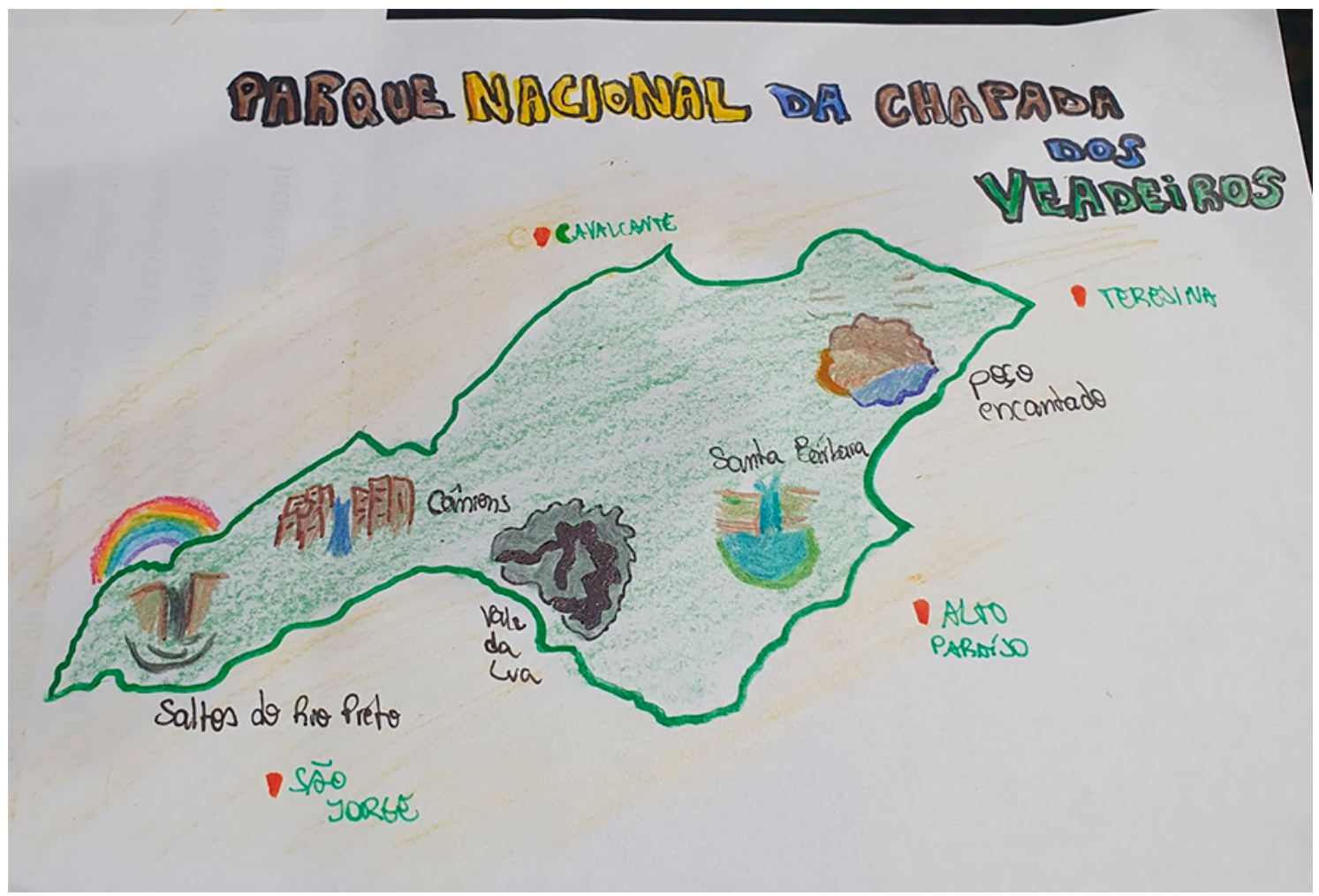

Figura 14: Mapas — "Pontos turísticos in Paris", criação de Renan Marques

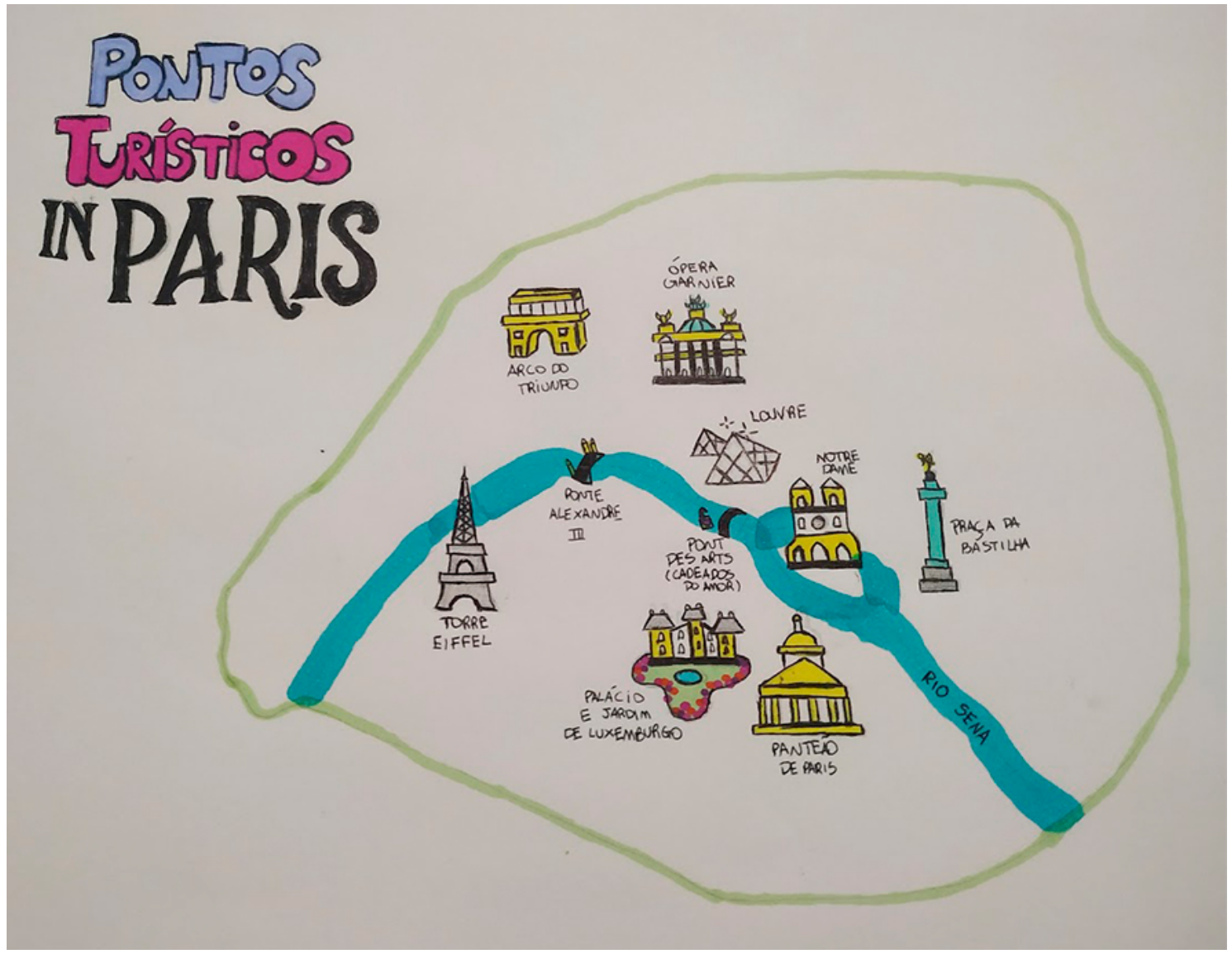


O oitavo modulo, sobre visualização de dados, apresentou princípios fundamentais, boas práticas e aspectos retóricos (Cairo, 2016, 2019; Wong, 2010; Emanuel, 2010; Huff, 1954). A atividade foi a criação de uma visualização de dados pessoal e humanizada, inspirada pelo projeto Dear Data (Lupi e Posavec, 2016). Cada aluno deveria escolher algo relacionado a si mesmo que pudesse ser contabilizado, ou seja, mensurado em quantidade de unidades, por exemplo:

- Quantos tênis eu tenho?

- Quantas pessoas moram no meu prédio?

- Quantos chefes eu tive?

Depois de contar os itens, deveriam escolher alguns pontos para destacar, como:

- Dos tênis que eu tenho, quantos são estampados e quantos são lisos? Tem algum que nunca foi lavado?

- Das pessoas do meu prédio, quantas eu conheço?

Quantos são meus amigos?

Quantos já me emprestaram algo?

- Dos chefes que eu tive, quantas eram mulheres?

Algum já me demitiu?

Algum fez algum tipo de assédio?

A visualização de dados deveria usar aspectos retóricos para trazer o leitor ao tema. $\mathrm{O}$ exercício aplicava os conceitos discutidos e trazia, como componente lúdico e emocional, um olhar para si e para o próprio cotidiano. As visualizações trataram de assuntos variados, desde relações com filmes e livres favoritos até o tempo passado com a família durante a pandemia. 
Figura 15: Dados — "Momentos da vida em que li Harry Potter e meus personagens favoritos", criação de Bruna Rangel

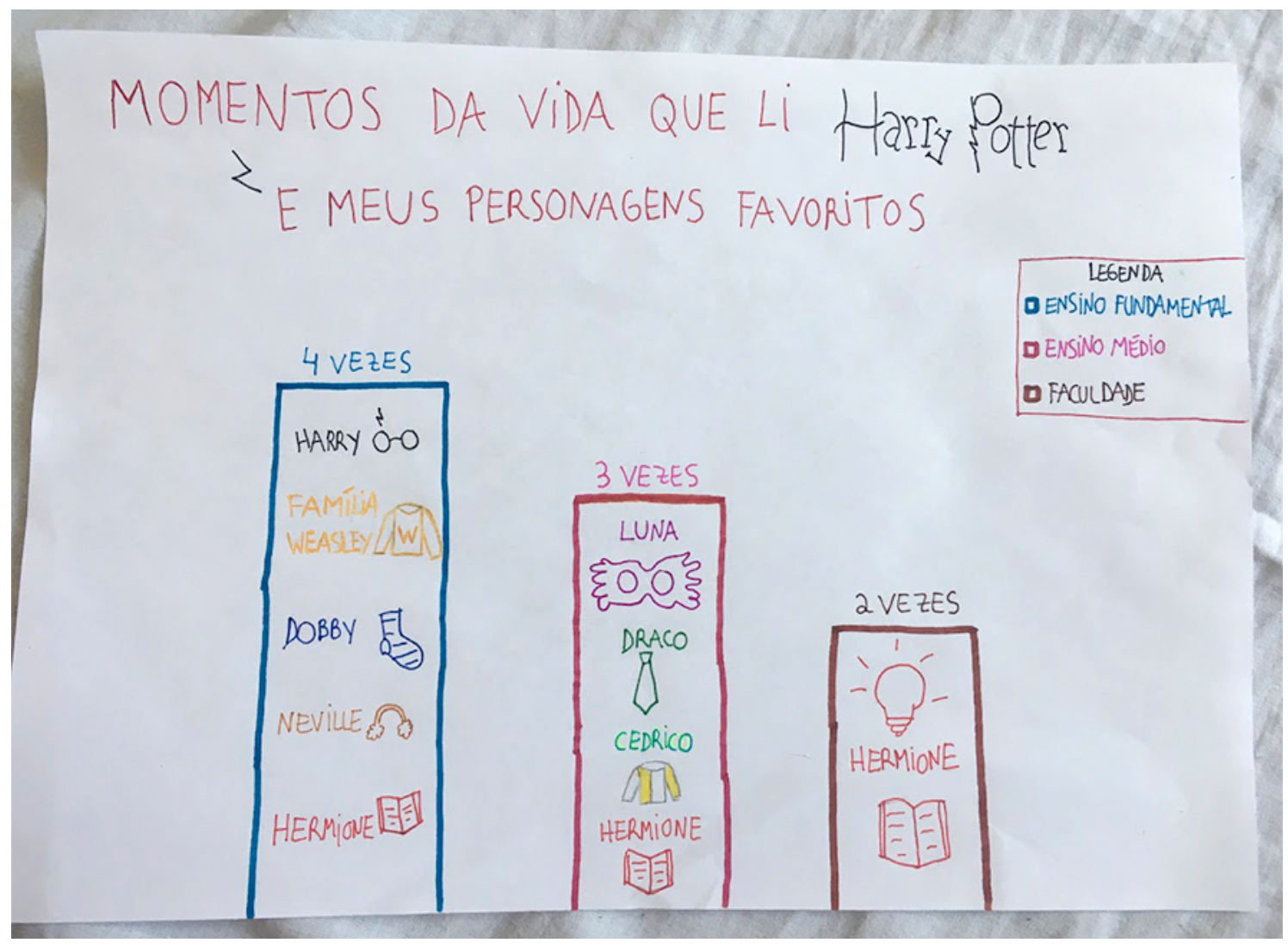


Figura 16: Dados — "Tempo com minha família", criação de Sasha de Lima

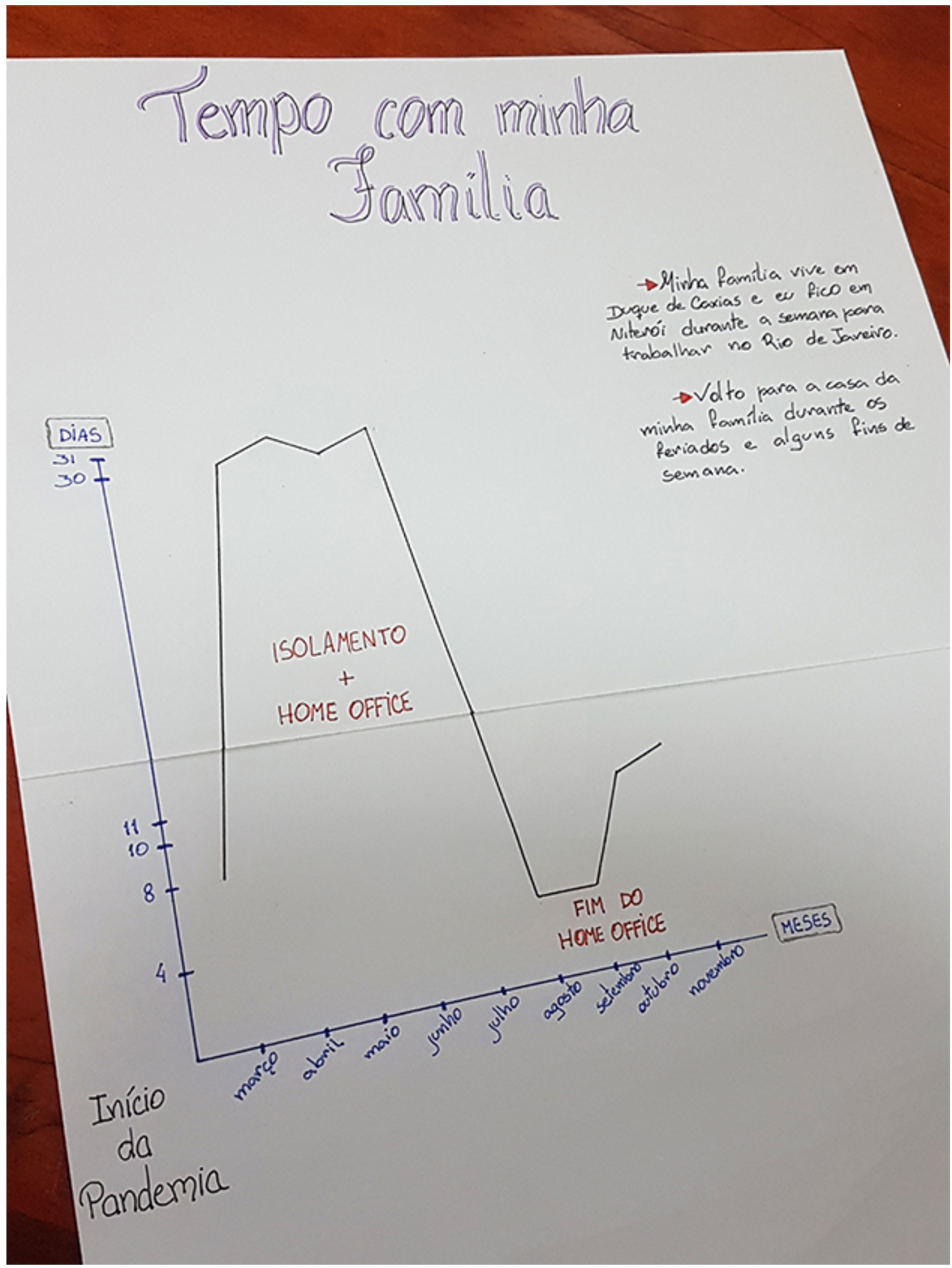

O módulo de fechamento teve avaliação de desempenho pela professora, pelo próprio aluno e pelos pares. Foram consideradas a execução das atividades e a colaboração com comentários nas postagens dos colegas. Na autoavaliação, foi pedido ainda que os alunos considerassem o aprendizado pessoal, avaliando o quanto aprenderam na disciplina. Como avaliação por pares, foi pedido apenas destaques positivos, ou seja, alunos poderiam indicar 
colegas que tiveram atividades especialmente bem-sucedidas e/ou comentários especialmente relevantes e úteis.

\section{Discussão}

Apesar de ter sido desenvolvida em um momento de emergência e incertezas, a disciplina foi um espaço de experimentação de pontos relevantes para o ensino de modo geral, e não apenas na pandemia: a aplicação de princípios da educação online; a relação entre prática digital e analógica; componentes emocionais na aprendizagem; e questões de acessibilidade.

Consideremos os oito princípios da Educação Online (Pimentel \& Carvalho, 2020) e como foram aplicados na disciplina.

1) O conhecimento como "obra aberta" pode ser observado na construção do conteúdo colaborativo, a partir das discussões e produções dos alunos.

2) A curadoria de conteúdos online aconteceu não apenas no conteúdo complementar proposto por mim em cada módulo, mas também nas colaborações espontâneas dos próprios alunos, que postaram recomendações de sites, livros, filmes e séries relacionadas aos assuntos tratados.

3) O uso de ambiências computacionais diversas incluiu, além do ambiente virtual de aprendizagem, um blog da disciplina, um canal no YouTube, e interações no Instagram e no Twitter, além do uso do smartphone como câmera fotográfica.

4) A aprendizagem colaborativa deu-se na produção conjunta de sentido e nas críticas construtivas feitas pelos alunos nos trabalhos dos colegas.

5) A conversação entre todos deu-se de forma síncrona e assíncrona, no ambiente virtual de aprendizagem e em redes sociais.

6) As atividades autorais foram a base da disciplina, com os exercícios de criação executados nos módulos.

7) A mediação docente ativa aconteceu com comentários e engajamento, de forma aberta e acolhedora ao longo da disciplina, equilibrando presença e espaço para que os alunos interagissem entre si.

8) A avaliação baseada em competências, formativa e colaborativa deu-se com a combinação da avaliação docente de atividades e comentários ao longo da disciplina, com a autoavaliação e a avaliação por pares, feitas pelos alunos.

A proposta de independência do computador, atendendo aos alunos que tinham pouco ou nenhum acesso ao dispositivo, trouxe outras vantagens, a saber: tempo de descanso do uso de telas e exercício de tomada de decisões, já que não tinham modelos digitais disponíveis. Os relatos dos alunos sobre a disciplina e as atividades giraram em torno da diversão e do relaxamento, principalmente como momentos de respiro em oposição a uma grande quantidade de horas diárias em frente a telas, para estudo, trabalho e lazer. A liberdade de escolha de materiais foi aproveitada como uma oportunidade de experimentação, com o uso de 
linhas de costura, esmaltes, maquiagem, papéis e diferentes tipos de pigmento. A orientação das atividades explicitou a importância dos aspectos comunicacionais, em vez da destreza ou virtuosismo na execução. Produzi, em todas as atividades, exemplos simples como demonstração, deixando evidente que não era esperado um nível profissional de ilustração. Assim, os alunos puderam relaxar e se concentrar nas estratégias de visualização. Em outras disciplinas, que utilizaram aplicativos e softwares de criação digital, observei uma certa repetição de elementos, que eram disponibilizados como modelos, objetos ou configuraçõespadrão pelos programas. Nesta disciplina, em comparação, houve uma grande variedade de soluções, já que a execução era analógica e partia completamente do aluno.

Em relação aos componentes emocionais da disciplina, os alunos responderam positivamente, tanto nos momentos de avaliação da disciplina, propostos por mim, quanto em declarações espontâneas. Os principais aspectos destacados foram o uso de referências pop nos conteúdos, os temas lúdicos e pessoais nas atividades, e a conversação informal e baseada no acolhimento, tanto na interação professora-alunos quanto entre os alunos.

\section{Considerações finais}

O período inicial da pandemia, com todas as suas imposições e incertezas, trouxe dificuldades para o ensino, como a impossibilidade de aulas presenciais. Para o ensino de Design de Informação, especificamente, há a dificuldade de acesso a computadores e softwares de criação, já que não podemos usar os laboratórios de informática das instituições de ensino. Além disso, tanto máquinas quanto os softwares mais usados no mercado são caros, o que torna sua aquisição proibitiva para grande parte dos alunos.

Desta crise pode surgir, no entanto, oportunidades de inovação. Os princípios da Educação Online, orientados para o ensino não-presencial, podem ser aplicados também no retorno ao ensino presencial, seja diretamente, formando uma espécie de ensino híbrido, ou como inspiração para novas atuações em sala de aula.

Atividades de criação com materiais analógicos já estão tradicionalmente presentes nos cursos de Design, mas foram paulatinamente sendo substituídas pelo uso de softwares. Embora a criação digital seja essencial para a formação dos profissionais da área, ela pode ser acompanhada de exercícios analógicos, voltados não para a capacitação técnica, mas para o desenvolvimento de habilidades conceituais e estratégicas.

Os componentes emocionais e lúdicos, como os alívios cômicos no conteúdo e os temas pessoais nas atividades, foram fundamentais para o período de medo e tristeza da pandemia. Além de serem momentos de respiro para os alunos, eles abriram oportunidades de conexão pessoal, tão necessária em tempos de isolamento. Em um eventual retorno presencial, podem continuar sendo usados - destas e de outras maneiras - para os mesmos fins.

A experiência da disciplina, aqui relatada, levantou possibilidades e desafios não apenas do ensino não-presencial em uma época de emergência, como também do ensino em si e, especificamente, em uma disciplina prática. Acredito que tanto os resultados bem-sucedidos 
como os pontos de dificuldade foram lições aprendidas para as próximas edições desta disciplina, assim como em outras disciplinas também. Que elas venham em tempos mais leves e felizes.

\section{Agradecimento}

Agradeço aos alunos que participaram da disciplina, especialmente aos que gentilmente permitiram a reprodução de imagens neste trabalho.

\section{Referências}

Albers, J. (1975). Interaction of Color. New Haven: Yale University Press.

Cairo, A. (2016). The Truthful Art: data, charts, and maps for communication. San Francisco: New Riders.

Cairo, A. (2019). How Charts Lie: Getting Smarter about Visual Information. New York: W. W. Norton \& Company.

Cann, H. (2018). How to make hand-drawn maps. San Francisco: Chronicle Books.

Dondis, D. A. (2003). Sintaxe da linguagem visual. São Paulo: Martins Fontes.

Emanuel, B. (2010). Rhetoric in Graphic Design. Master Thesis. Dessau, Alemanha: Hochschule Anhalt.

Fraser, T., \& Banks, A. (2007). O guia completo da cor: livro essencial para a consciência das cores. São Paulo: Editora Senac.

Frutiger, A. (2001). Sinais \& Símbolos: Desenho, projeto e significado. São Paulo: Martins Fontes.

Hancock, J. G., Haworth, H., Hill, S., \& King, S. (2018). The art of map illustration. Lake Forest: Quarto Publishing Group.

Holtzschue, L. (2011). Understanding Color: An Introduction for Designers. Hoboken: John Wiley \& Sons.

Huff, D. (1954). How to lie with statistics. New York: W.W. Norton \& Company.

Itten, J. (2001). The Elements of Color. New York: John Wiley \& Sons.

Krygier, J., \& Wood, D. (2011). Making Maps: A Visual Guide to Map Design for GIS. New York: The Guilford Press.

Lupi, G., \& Posavec, S. (2016). Dear Data: A Friendship in 52 Weeks of Postcards. New York: Princeton Architectural Press.

Lupton, E., \& Philips, J. C. (2015). Novos fundamentos do design. São Paulo: Cosac Naify.

McCloud, S. (2005). Desvendando os Quadrinhos. São Paulo: M.Books.

Monmonier, M. (1996). How to Lie with Maps. Chicago: The University of Chicago Press.

Pimentel, M., \& Carvalho, F. (2020). Princípios da Educação Online: para sua aula não ficar massiva nem maçante! Acesso em 17 de novembro de 2020, disponível em SBC Horizontes: http://horizontes.sbc.org.br/index.php/2020/05/principios-educacao-online 
Roam, D. (2008). The Back of the Napkin. New York: Portfolio / Penguin Group.

Santos, E. (2009). Educação online para além da EAD: um fenômeno da cibercultura. Actas do $X$ Congresso Internacional Galego-Português de Psicologia. (pp. 5658-5671). Braga:

Universidade do Minho.

Tyner, J. A. (2010). Principles of Map Design. New York: The Guilford Press.

Wong, D. M. (2010). The Wall Street Journal guide to information graphics: the dos and don'ts of presenting data, facts, and figures. New York: W. W. Norton \& Company.

\section{Sobre a autora}

Bárbara Emanuel, Dra ., UFF, Brasil <be@id.uff.br> 